\title{
Illusory movements of the contralesional hand in patients with body image disorders
}

\author{
M Zampini, V Moro, S M Aglioti
}

J Neurol Neurosurg Psychiatry 2004;75:1626-1628. doi: 10.1136/jnnp.2003.028589

Objectives: In the present study, we assess whether illusory sensations of movement can be elicited in patients with right brain damage (RBD).

Methods: Ten RBD patients (three with disorders of bodily representations) were asked to report whether movements of their right hand induced any illusory somatic or motor sensations. Inquiries on anomalous sensation of movement of the left hand were carried out while subjects: 1) observed the moving hand in a mirror propped vertically along the parasagittal plane; 2) looked directly at the moving hand; 3) looked at the still hand; 4) kept their eyes closed. Twelve healthy subjects served as controls.

Results: Movement of the right hand induced a very clear sensation of movement of the left, contralesional hand in two patients affected by body image disorders. Remarkably, this occurred mainly while subjects were looking in the mirror, that is, when conflicts between visual, somatic, and motor information were maximal. In no condition did control subjects report any consistent anomalous evoked movement or sensation.

Conclusions: Illusory movements of the left, plegic hand contingent upon sensorimotor conflicts can be evoked in brain damaged patients with body image disorders.

$\mathrm{S}$ udies in amputee patients show that somatic stimuli are referred to body areas remote from the stimulation site. $^{1-6}$ Double sensations have also been reported in patients with unilateral brain damage with somesthetic deficits who referred to the anesthetic hand pressure stimuli delivered to the normal hand. ${ }^{7}$ Interestingly, these intermanual referrals occurred mainly when patients looked at the mirror reflection of their stimulated hand. ${ }^{7}$ Moreover, research on amputee patients has reported that voluntary movements of the one hand viewed in the mirror induced the strong illusion of resurrection of movements of the phantom, which was previously perceived in a fixed position. ${ }^{8}$ Although patients with lesions in the peripheral or central nervous system ${ }^{9}$ or with psychiatric diseases ${ }^{10}$ may report the anomalous lack of awareness of certain aspects of motor control, so far most studies on evoked illusions or hallucinations have focused on senso-perceptions rather than on movements.

The present study focused on evoked illusions of movement in patients with right brain damage. The aim of the study was to assess whether: 1) intermanual illusory movements can be induced; 2) visual inputs dominate over somatic and motor signals in determining illusory motor phenomena; or 3) reports of illusory movements are associated with clinical indices of sensorimotor, spatial, or body image disorders.

\section{MATERIALS AND METHODS}

We tested 10 RBD patients ( 3 females and 7 males, mean age 58 years, range $27-75$, mean education 10 years; lesion test interval: mean 68 days, range 19-128 days) recruited from the Neurorehabilitation Unit of the Ospedale 'Sacro Cuore', (Negrar, Verona, Italy). All patients were right handed by their own verbal report and performed within normal limits on the Mini-Mental State Examination. ${ }^{11}$ Twelve healthy subjects matched for age ( 5 females and 7 males, mean age 55 years, range 26-74), education (mean 9 years), and handedness served as controls. All subjects gave their informed consent and none of them was informed about the aims of the experiment. The procedures were approved by the local ethical committee.

Each patient underwent a standard neurological examination to assess the presence of motor deficits, visual and tactile extinction, and visual field defects. ${ }^{12}$ Somatic deficits were assessed by testing tactile, thermal, pallesthetic, and kinesthetic sub-modalities. Visual neglect was examined by means of a cancellation test, ${ }^{13}$ a reading test, ${ }^{14}$ and two tests of reproduction of drawings from copying and from memory. ${ }^{12}$ Personal neglect was examined by the Comb and Razor test. ${ }^{15}$ Anosognosia for hemiplegia, disownership of the plegic hand, and supernumerary phantom limb phenomena were assessed by means of questionnaires prepared ad hoc. The presence of a deficit in each body related test was scored 1. Thus, a body image disorder score (BIDS) was computed (range: 0-4). Additional clinical information for each patient is reported in tables 1 and 2 .

Subjects sat in a quiet room with their hands resting on a table. Three experimental conditions were carried out. In the first, active movements were investigated. In particular, each subject was requested to perform flexo-extension movements of the wrist with the right hand. Passive movements were examined in the other two conditions. In the first condition, flexo-extension movements were induced by an experimenter who sat on the subject's right and held his/her right hand. In the second condition, the experimenter induced flexoextension movement of the left hand.

For each experimental condition, four different blocks were performed. Subjects could: a) look at the moving right hand in a mirror propped vertically along the parasagittal plane; b) look directly at the moving hand; c) look at the still hand during execution of movements by the other hand; or d) keep their eyes closed while active or passive movements were performed. At the beginning of each block (lasting $3 \mathrm{~min})$, subjects were instructed to report any type of "anomalous" sensation or movement in any part of the body (if they felt any).

In each condition, the beginning and the end (in sec) of illusory movements or evoked somatic sensations was

Abbreviation: $R B D$, right brain damaged 
Table 1 Clinical and radiological information of patient group, scores in bold indicate presence of deficit

\begin{tabular}{|c|c|c|c|c|c|c|c|c|c|c|c|c|}
\hline Patients & MMSE & $\begin{array}{l}\text { Motor } \\
\text { score }^{*}\end{array}$ & $\begin{array}{l}\text { Sensory } \\
\text { score† }\end{array}$ & $\begin{array}{l}\text { Visual } \\
\text { neglect } \\
\text { score† }\end{array}$ & $\begin{array}{l}\text { Visual } \\
\text { extinction } \ddagger\end{array}$ & $\begin{array}{l}\text { Tactile } \\
\text { extinctionł }\end{array}$ & $\begin{array}{l}\text { Personal } \\
\text { neglect‡ }\end{array}$ & Anosognosiał & Disownł & $\begin{array}{l}\text { Sup. } \\
\text { limb‡ }\end{array}$ & $\begin{array}{l}\text { BID } \\
\text { score† }\end{array}$ & Lesion \\
\hline 1 & 26 & 3 & 3 & 3 & 1 & 1 & 1 & 1 & 0 & 0 & 2 & see fig 1 \\
\hline 2 & 25 & 3 & 4 & 3 & 1 & 1 & 1 & 0 & 1 & 1 & 3 & see fig 1 \\
\hline 3 & 26 & 3 & 4 & 3 & 1 & 1 & 0 & 0 & 0 & 0 & 0 & Temporal \\
\hline 4 & 25 & 3 & 4 & 4 & 1 & 1 & 0 & 1 & 0 & 0 & 1 & Basal ganglia \\
\hline 5 & 26 & 1 & 0 & 3 & 1 & 0 & 0 & 0 & 0 & 0 & 0 & Frontotemporal \\
\hline 6 & 28 & 2 & 4 & 0 & 0 & 1 & 0 & 0 & 0 & 0 & 0 & $\begin{array}{l}\text { Thalamus, } \\
\text { internal capsule }\end{array}$ \\
\hline 7 & 30 & 3 & 1 & 0 & 1 & 1 & 0 & 0 & 0 & 0 & 0 & Frontal \\
\hline 8 & 28 & 1 & 0 & 1 & 0 & 0 & 0 & 0 & 0 & 0 & 0 & Frontal \\
\hline 9 & 30 & 1 & 1 & 0 & 0 & 0 & 0 & 0 & 0 & 0 & 0 & Pariental \\
\hline 10 & 30 & 1 & 0 & 1 & 1 & 0 & 0 & 0 & 0 & 0 & 0 & Basal ganglia \\
\hline
\end{tabular}

MMSE, Mini-mental state examination; cut-off, 24/30; Disown, disownership of the plegic arm; Sup. Limb, supernumerary limb; BID, body image disorders ${ }^{*} \mathrm{O}=$ absence of deficit- $3=$ total loss of movement; ffor each test a defective performance was scored 1 point; $¥ 0=$ absence of deficit- $1=$ presence of deficit.

recorded by means of a manually operated chronometer. The order of the experimental conditions and blocks was counterbalanced across subjects.

\section{RESULTS}

In no condition did healthy subjects report any type of referred sensation. Therefore, their performance will not be further analysed. Patients 1 and 2, who presented with large cortical and subcortical frontotemporo-parietal lesions (see fig 1), referred clear illusory movements of the still, plegic hand (see table 2).

According to patients' reports, illusory movements of the left, plegic hand mirrored movements of the ipsilesional, right hand. As reported in table 2, illusory movements started

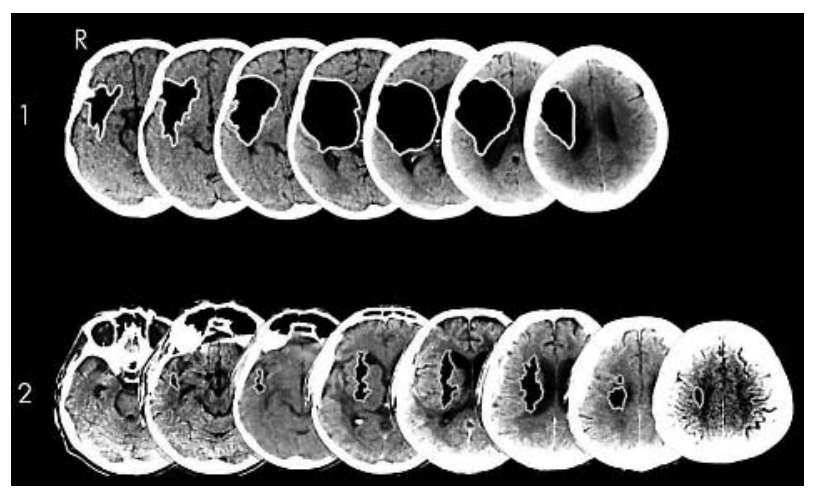

Figure 1 Select Computed tomography slices showing site and size of lesions in patients 1 and 2 . White lines delimit lesions. earlier and lasted longer in conditions in which conflicts between visual inputs and somatomotor signals were maximal. Indeed, it can be postulated that in the mirror conditions proprioceptive and motor feelings originating from the right hand are attributed to the image reflected in the mirror and thus perceived as that of a left hand. Thus, a clear mismatch between sensorimotor and visual information should occur in this condition.

In the virtually no conflict, closed eye condition, no patient ever reported anomalous movements. It is worth noting that patients 1 and 2 not only presented with severe somatic deficits but also with body image disorders inferred from the presence of personal neglect, anosognosia for hemiplegia, disownership phenomena, and feeling of a supernumerary limb on the contralesional side. A series of correlation analyses between the presence of illusory mirror movements and scores in the different clinical tests was carried out by means of the non-parametric Spearman test. Although no correlation was found with signs of extrapersonal neglect, the two patients who felt illusory mirror movements presented with personal neglect. Importantly, a significant positive correlation was found between illusory movements and body image disorder scores (rho $(10)=0.857 ; \mathrm{p}=0.0015$ ).

No patient reported intermanual referrals of illusory movements of the contralesional, right hand during passive movements of the ipsilesional, left hand. It must be noted, however, that three patients (1,2, and 4; see table 1$)$ reported a clear sensation of muscle contraction of the ipsilesional hand in conditions in which the contralesional hand was passively moved. Notably, this happened only in the "mirror" and in the "look at the moving hand" blocks. Although covert contractions may have accompanied this phenomenon, the experimenter detected no overt contractions.

Table 2 Duration and latency (s) of illusory movement of the left, plegic hand during movements of the right hand in the different experimental conditions and blocks

\begin{tabular}{|c|c|c|c|c|c|c|c|c|c|}
\hline \multirow[b]{2}{*}{ Patients } & \multirow{2}{*}{$\begin{array}{l}\text { Illusory } \\
\text { movements }\end{array}$} & \multicolumn{2}{|c|}{ Look in the mirror } & \multicolumn{2}{|c|}{$\begin{array}{l}\text { Look at the right moving } \\
\text { hand }\end{array}$} & \multicolumn{2}{|c|}{ Look at the left still hand } & \multicolumn{2}{|c|}{ Eyes closed } \\
\hline & & Active & Passive & Active & Passive & Active & Passive & Active & Passive \\
\hline \multirow[t]{2}{*}{1} & duration & 122 & 50 & - & 144 & - & 70 & - & - \\
\hline & latency & 58 & 130 & - & 36 & - & 110 & - & - \\
\hline \multirow[t]{2}{*}{2} & duration & 165 & 100 & - & - & - & - & - & - \\
\hline & latency & 15 & 80 & - & - & - & - & - & - \\
\hline
\end{tabular}

Duration and latency (in seconds) of illusory movement of the left, plegic hand during movements of the right hand in the different experimental conditions and blocks.

- , absence of illusion. 
Six patients (including the two with illusory mirror movements) occasionally reported very vague tingling, tickling, or pain sensations referred to the contralesional or ipsilesional body part. However, these sensations were rare and were not linked to any particular testing condition.

\section{DISCUSSION}

The present study shows for the first time that selective illusory movements of the contralesional, left hand contingent upon active or passive movements of the ipsilesional, right hand can be induced in patients with body image disorders. Patients provided detailed reports on the type and the duration of the illusory phenomenon; they also agreed that the illusory movements of the plegic, left hand were identical to those felt in the ipsilesional, right hand. It is worth noting the absence of illusory movements referred to the plegic hand when eyes were closed and referred to the ipsilesional hand during examiner induced movements of the plegic hand. Taken together, this evidence contributes to ruling out the possibility that the effect is non specific. Indeed, under these testing conditions possible confounding signals originating from the plegic, left hand were kept under control by the preserved representations of the ipsilesional, right hand. Moreover, in no testing conditions were illusory movements or sensations induced in healthy subjects or, most importantly, in the patients with brain damage with no bodily disorders. Notably, for patients 1 and 2 illusory movements lasted longer and were more vivid when active or passive movements of the ipsilesional hand were seen reflected in the mirror. Under these conditions, the visual information coming from the mirror reflection of the moving right hand is considered veridical in spite of the mismatch of between hand proprioceptive signals. These results, showing the predominance of illusory evoked movements in the mirror blocks, expand on research carried out with mirrors to relieve pain in amputee subjects ${ }^{68}$ and in patients with acute complex regional pain syndrome. ${ }^{16}$ Moreover, mirror reflected inputs have been used to try to facilitate the recovery of hemiparetic patients. ${ }^{17} 18$

It is important to emphasise that in this research no correlations were found between the presence of illusory movements and somatomotor, visual deficits, or extrapersonal neglect. In contrast, a clear correlation was found with disorders of bodily representations. This suggests that phantom movements are not generated in primary cortices but are probably linked to higher order, multimodal areas concerned with the integration of primary inputs into a unitary image of the body.

Finally, vision seems to be crucial for eliciting phantom movements of the contralesional, left hand, given that no illusions were reported in the closed eyes blocks. Our results may have to do with the visual capture phenomena which drive subjects to rely on vision more than on somatic senses such as proprioception. ${ }^{19} 20$

\section{ACKNOWLEDGEMENTS}

Financial support from the HFSP, CNR, and MIUR, Italy to SMA is gratefully acknowledged. Thanks are due to Mr Marco Veronese for preparing the figure.

\section{Authors' affiliations}

M Zampini, Department of Experimental Psychology, University of Oxford and Dipartimento di Scienze Neurologiche e della Visione, Sezione di Fisologia, Universita' di Verona

V Moro, Dipartimento di Psicologia ed Antropologia Culturale, Universita'di Verona

S M Aglioti, Dipartimento di Psicologia, Universita' di Roma "La Sapienza" and Centro Ricerche Neuropsicologia, IRCCS, Fondazione Santa Lucia, Roma

Competing interests: none declared

Correspondence to: Dr S M Aglioti, Dipartimento di Psicologia, Universita' di Roma "La Sapienza", Via dei Marsi 78, 00185, Roma; salvatoremaria.aglioti@uniromal.it

Received 18 September 2003

Accepted in revised form 21 January 2004

\section{REFERENCES}

1 Aglioti S, Bonazzi A, Cortese F. Phantom lower limb as a perceptual marker of neural plasticity in the mature human brain. Proc R Soc Lond B Biol Sci 1994;255:273-78.

2 Aglioti S, Cortese F, Franchini C. Rapid sensory remapping in the adult human brain as inferred from phantom breast perception. Neuroreport 1994:5:473-6.

3 Aglioti SM, Beltramello A, Peru A, et al. Anomalous double sensations after damage to the cortical somatosensory representation of the hand in humans. Neurocase 1999;5:285-92.

4 Knecht S, Soros P, Gurtler S, et al. Phantom sensations following acute pain. Pain 1998:77:209-13.

5 Pons T, Garraghty PE, Ommaya AK, et al. Massive cortical reorganization after sensory deafferentation in adult macaques. Science 1991;252:1857-60.

6 Ramachandran VS, Rogers-Ramachandran D, Cobb S. Touching the phantom limb. Nature 1995;377:489-90.

7 Sathian K. Intermanual referral of sensation to anesthetic hands. Neurology 2000;54: 1866-68.

8 Ramachandran VS, Rogers-Ramachandran D. Synaesthesia in phantom limbs induced with mirrors. Proc $R$ Soc Lond B Biol Sci 1996;263:377-86.

9 Berlucchi G, Aglioti S. The body in the brain: neural bases of corporeal awareness. Trend Neurosci 1997;20:560-64.

10 Frith CD, Blakemore S, Wolpert DM. Explaining the symptoms of schizophrenia: abnormalities in the awareness of action. Brain Res Brain Res Rev 2000;31:357-63.

11 Folstein MF, Folstein SE, McHugh PR. 'Mini mental state'. A practical method for grading the cognitive state of patients for the clinicians. Journal of Psychiatric Research 1975;12:189-98.

12 Aglioti SM, Smania N, Peru A. Frames of reference for mapping tactile stimuli in brain-damaged patients. J Cogn Neurosci 1999;11:67-79.

13 Albert ML. A simple test of visual neglect. Neurology 1973;23:658-64

14 Barbieri C, De Renzi E. Patterns of neglect dissociation. Behav Neurol 1989;2:13-24.

15 Mclntosh RD, Brodie EE, Beschin N, et al. Improving the clinical diagnosis of personal neglect: a reformulated comb and razor test. Cortex 2000;36:289-92

16 McCabe CS, Haigh RC, Ring EF, et al. A controlled pilot study of the utility of mirror visual feedback in the treatment of complex regional pain syndrome (type 1). Rheumatology 2003;42:97-101.

17 Altschuler EL, Wisdom SB, Stone L, et al. Rehabilitation of hemiparesis after stroke with a mirror. Lancet 1999;353:2035-6.

18 Sathian K, Greenspan Al, Wolf SL. Doing it with mirrors: a case study of a novel approach to neurorehabilitation. Neurorehabil Neural Repair 2000;14:73-6.

19 Holmes N, Crozier G, Spence C. When mirrors lie: 'Visual capture' of arm position impairs reaching performance. Cogn Affect Behav Neurosci (in press).

20 Welch RB, Warren DH. Immediate perceptual response to intersensory discrepancy. Psychol Bull 1980;3:638-67. 